\title{
Association Study between Proinflammatory Cytokine Gene Polymorphism and Risk of Recurrent Spontaneous Abortion
}

\author{
LI YE ZHU AND MIAN PING CHEN ${ }^{1 *}$ \\ Department of Obstetrics, Maternal and Child Hospital of Haidian District, No. 33, Haidian South Road, Beijing 100080, \\ ${ }^{1}$ Department of Laboratory Medicine, Haikou Hospital of the Maternar and Child Health, No. 6, Wentan Road, Haikou, Hainan \\ 570203, China
}

Zhu et al.: Study between Proinflammatory Cytokine Gene Polymorphism and Risk of RSA

\begin{abstract}
To investigate the correlation between inflammatory cytokine gene polymorphisms and the risk of recurrent miscarriage. A total of 120 patients with recurrent spontaneous abortion in our hospital between January 2019 and December 2020 were selected as the recurrent spontaneous abortion group and 120 healthy pregnant women with early pregnancy who visited the hospital during the same period were used as the control group and the genotype of interleukin-18 was detected by single nucleotide polymorphism typing technique and the validation method was Hardy Weinberg's law of genetic equilibrium was used to verify the genotype of interleukin-18 and the relationship between interleukin-18 genotype and the risk of recurrent spontaneous abortion was analyzed by logistic method. The results showed that the level of interleukin-18 in the recurrent spontaneous abortion group was significantly higher than that in the control group $(p<0.05)$; the actual genotype frequencies of interleukin-18 (rs1946519) and interleukin-18 (rs360717) in the Recurrent spontaneous abortion group were not significantly different from the theoretical values by test (test values of 0.917 and 0.126 , respectively, $p>0.05$ ); the interleukin-18 (rs1946519) and interleukin18(rs360717) in the control group The actual genotype frequencies of interleukin-18(rs1946519) and interleukin-18 (rs360717) in the control group were also not significantly different from the theoretical values (test values were 0.474 and $0.153, p>0.05$ ); the genotypes of the rs 1946519 and rs360717 loci showed significant differences and the recurrent spontaneous abortion group had significantly more $A$ alleles than the control group $(p<0.05)$; rs1946519 and rs360717 locus mutant cases showed significant differences in serum interleukin-17 levels, with AA and TT genotypes showing higher concentrations than other genotypes, respectively $(p<0.05)$; the relative risk of recurrent spontaneous abortion risk in rs1946519 AG and AA gene carriers was 2.468 and 2.468 times higher than that of the GG allele, respectively. The relative risk of recurrent spontaneous abortion in rs360717 TC and TT gene carriers was 1.973 and 1.545 times higher than that of $\mathrm{CC}$ allele, respectively and all of them had higher risk of recurrent spontaneous abortion $(p<0.05)$. The rs1946519 polymorphic allele $G$ and rs360717 allele $C$ mutations of interleukin-18 affect the serum hormone levels of patients and lead to an increased risk of recurrent spontaneous abortion in pregnant women. Therefore, interleukin-18 gene polymorphisms may be an important basis for the pathogenesis of recurrent spontaneous abortion and its treatment.
\end{abstract}

Key words: Recurrent miscarriage, interleukin-18, gene polymorphism, risk level

Recurrent spontaneous abortion (RSA) refers to the occurrence of two or more abortions before $20 \mathrm{w}$ of pregnancy. The incidence rate of RSA in China is about $5 \%$ of that of women of childbearing age, which seriously affects the outcome of pregnancy and the family harmony ${ }^{[1]}$. The etiology of RSA mainly includes genetics, endocrinology, anatomy, immunology, microbiology and thrombotic diseases. In view of the complex pathogenesis, RSA is still the focus and difficulty in clinical and scientific research. In recent years, studies have found that maternal fetal immune imbalance has a great relationship with RSA. The level of proinflammatory factors in RSA patients is significantly higher than that in normal pregnant women. Proinflammatory factors can promote downstream neutrophil aggregation, aggravate the

*Address for correspondence

E-mail: h10021310@163.com 
damage of endometritis, and aggravate the risk of abortion $^{[2-5]}$. These results suggest that proinflammatory factors may play an important role in the occurrence and development of RSA. It has been reported that Interleukin-18 (IL-18) gene polymorphism in proinflammatory factor family is related to development and clinical process of human diseases. Among them, rs1946519 and rs360717 are polymorphic genes in the coding region of pro-inflammatory factor IL-18, which are closely related to the secretion of pro-inflammatory factors ${ }^{[6]}$. Based on the above results, this study selected IL-18 gene of different loci to investigate, in order to reveal the relationship between proinflammatory gene polymorphism and RSA and provide reference for early diagnosis and prevention of RSA. The patients included in this study were divided into RSA group and control group. There was no significant difference in age and gestational age between the two groups ( $p>0.05$ ). Total 120 patients with RSA from January 2019 to December 2020 were selected as RSA group, with an average age of (31.2 \pm 4.3$) \mathrm{y}$; (22-40 y). Inclusion criteria-The patient had more than two spontaneous abortions, no live birth history; No abnormal uterine and cervical lesions; The couple were not close relatives, no embryo chromosome abnormalities, no family genetic history; No genital tract infection; No endocrine metabolic diseases and autoimmune diseases; No abnormal semen routine examination; The menstrual cycle was basically stable and the ultrasound monitoring showed that the ovulation was normal. Meanwhile, 120 healthy pregnant women (23-40 y old, average $31.7 \pm 5.4$ y old) were selected as the control group. Exclusion criteria- Healthy early pregnant women with normal pregnancy history and willing to terminate pregnancy at the same time were selected; the study was approved by the hospital ethics committee and all patients' written consent was obtained. $3 \mathrm{ml}$ of the two groups were collected for DNA extraction and another $3 \mathrm{ml}$ of centrifuged venous blood serum was used for IL-18 level detection. DNA was extracted by leukocyte aggregation and genomic DNA was obtained in strict accordance with the instructions of the kit. Then the purity and concentration were determined by UV spectrophotometry. The SNP (multiple single base extension single nucleotide polymorphism) was used to detect the genotype of IL18. According to the corresponding sequence number, primers were designed with primer premier 5.0 software. The primer sequence of IL-18 (rs1946519) was as follows: 5'-AGGGATGTAAACAGGAAG-3' and 5'-GGAAACGGTCGCCCAGAT-3'. The sense and antisense primer sequences of IL-18 (rs360717) were 5'-AGGGAAAGATAAGGCTCG-3'

and 5'-CGTTCAGGTAAGAATGGG-3'. Polymerase chain reaction (PCR) detection-DNA samples containing $3 \mu \mathrm{L}$ and $10 \mu \mathrm{l}$ of RCR mixture containing primer, Deoxynucleotide triphosphates (dNTPs), Magnesium chloride $\left(\mathrm{MgCl}_{2}\right)$, ampli taqgold polymerase, DCTP and $1 \mu \mathrm{l} 10 \mathrm{X}$ buffer were taken and operated according to PCR standard procedures. Firstly, the mixture was pre denatured at $94^{\circ}$ for $2 \mathrm{~min}$; then the mixture was treated at $94^{\circ}$ for $30 \mathrm{~s}$, annealed at $60^{\circ}$ for $1 \mathrm{~min}$ and extended at $72^{\circ}$ for $1 \mathrm{~min}$, this cycle was repeated for 35 times. Finally, the final extension was performed at $72^{\circ}$ for $5 \mathrm{~min}$ to complete the amplification. PCR product purification: take $10 \mu \mathrm{l}$ of PCR product, add $2 \mathrm{U}$ Exonuclease I enzyme and 5'-USAp enzyme, water bath at $37^{\circ}$ for $60 \mathrm{~min}$, inactivate at $75^{\circ}$ for 12 min. Purification of elongation product-10 $\mu \mathrm{l}$ of elongation product was added with $1 \mathrm{U}$ of shrimp alkaline phosphatase (SAP) enzyme and then treated at $37^{\circ}$ for $60 \mathrm{~min}$ and $75^{\circ}$ for $12 \mathrm{~min}$. Finally, the gene sequence was determined by the gene sequence and 20 $\%$ of the samples were randomly and blindly selected for repeated detection to verify the gene sequence and the results were consistent with the initial analysis sequence. All data were analyzed by Statistical Package for the Social Sciences (SPSS) 22.0 software. Hardy Weinberg's law of genetic equilibrium was used to verify the genotype frequency. Chi square test was used to analyze the count data. T test or one-way Analysis of variance (ANOVA) was used to analyze the measurement data. Logistic regression was used to analyze the risk of IL-18 genotype and RSA. Odds ratio (OR) value and $95 \%$ confidence interval (CI) were used to express the relative risk. $\mathrm{p}<0.05$ was considered statistically significant. The results showed that the level of IL-18 in RSA group was significantly higher than that in control group $(\mathrm{p}<0.05)$, as shown in Table 1. Through the test, there was no significant difference between the actual genotype frequency and the theoretical value of IL-18 (rs1946519) and IL-18 (rs360717) in RSA group (test values were 0.917 and $0.126, p>0.05$ ) and there was no significant difference between the actual genotype frequency and the theoretical value of IL-18 (rs1946519) and IL-18

TABLE 1: COMPARISON OF SERUM HORMONE LEVELS BETWEEN THE TWO GROUPS

\begin{tabular}{lcc}
\hline Group & $\mathbf{n}$ & $\mathrm{IL}-18(\mathrm{ng} / \mathrm{L})$ \\
\hline RSA group & 120 & $45.28 \pm 11.24$ \\
Control group & 120 & $25.83 \pm 7.22$ \\
$\mathrm{t}$ & & 17.463 \\
$\mathrm{P}$ & & $<0.05$ \\
\hline
\end{tabular}


(rs360717) in control group (test values were 0.474 and $0.153, \mathrm{p}>0.05)$. The above results showed that the genetic balance between RSA group and control group was in accordance with Hardy Weinberg law. The results showed that the genotype of rs1946519 was significantly different, the A allele of RSA group was significantly more than that of the control group $(p<0.05)$, as shown in Table 2. In addition, the genotype of rs360717 of the two groups was also significantly different, the $\mathrm{C}$ allele of RSA group was significantly less than that of the control group $(p<0.05)$ and the specific distribution was shown in Table 3 . The levels of serum IL-17 in patients with rs 1946519 and rs360717 mutations were significantly different. The concentrations of AA genotype and TT genotype were higher than those of other genotypes $(\mathrm{p}<0.05)$, as shown in Table 4. Multiple regression analysis was performed with rs1946519 GG and rs360717 CC alleles as reference. We found that the relative risk of RSA in rs1946519 AG and AA carriers was 2.468 times and 2.712 times of GG allele, respectively and rs360717 TC and TT carriers were 1.973 times and 1.545 times of CC allele, respectively with higher risk (all $\mathrm{p}<0.05$ ), as shown in Table 5. RSA is one of the most common complications of early pregnancy and its pathogenesis mainly includes autoimmune diseases, endocrine abnormalities and gene abnormalities, but the specific mechanism has not been clarified ${ }^{[7]}$. It has been studied that the pathogenesis of RSA may be related to RSA gene polymorphism, such as immune and endocrine related genes ${ }^{[8]}$. Therefore, exploring the relationship between gene polymorphism and RSA is of positive significance for the diagnosis and treatment of RSA. The imbalance between regulatory cells and effector cells may lead to inflammation and eventually to implantation failure and other pregnancy related problems. The establishment and maintenance of this balance depends on the joint participation of a variety of cytokines and immune related cells ${ }^{[9]}$. Thelper cells 18 $\left(\mathrm{T}_{\mathrm{h}} 18\right.$ cells) is a new subset of CD4+T cells, which is characterized by the secretion of IL-18. It is effective for immune tolerance during pregnancy. Regulatory $\mathrm{T}$ cells (Tregs) are mostly produced by natural selection of CD4+T cells, which play an important role in the maintenance of immune self tolerance, immune homeostasis and the regulation of various physiological and pathological immune responses. Studies have shown that the proportion of Th18/Treg is relatively balanced in normal pregnancy environment and Th18 and Treg cells restrict each other to maintain a stable immune state. Once the balance is broken, the body's inflammatory response is difficult to control and the relative immune control ability is insufficient, thus inducing the occurrence of $\mathrm{RSA}^{[10,11]}$. Studies have shown that the number of Th18 cells in peripheral blood and endometrium of RSA women is more than that of Treg cells and the level of IL-18 in decidua tissue is higher than that of normal pregnant women ${ }^{[12]}$. IL-18 is derived from Th 18 cells and its family is composed of a variety of closely related cytokines, with high protein sequence similarity, the same receptor and similar biological activity ${ }^{[13]}$. Rs1946519 is located in the nuclear factor activated T cell (NFAT) binding motif of IL-18 gene. NFAT is the key regulator of IL-18 expression, which regulates IL-18 transcription and shows higher promoter activity ${ }^{[14]}$. Espinoza et al. ${ }^{[16]}$ showed that the presence of allele rs1946519 was associated with more effective IL-18 secretion, which may be due to the higher affinity of the generated sequence for NFAT. Rs360717 is another polymorphic gene located in the coding region of IL-18. Najafi et al. reported that rs360717 may be related to the high risk

TABLE 2: DISTRIBUTION OF RS1946519 GENE POLYMORPHISM IN TWO GROUPS

\begin{tabular}{lcccccc}
\hline Group & $\mathbf{n}$ & & Genotype & \multicolumn{2}{c}{ Allele } \\
\hline & & GG & AG & AA & G & A \\
RSA group & 120 & 18 & 58 & 44 & 94 & 146 \\
Control group & 120 & 36 & 52 & 32 & 124 & 116 \\
$\mathrm{t}$ & & & 14.075 & & & 12.189 \\
$\mathrm{P}$ & & & $<0.001$ & & \multicolumn{2}{c}{$<0.001$} \\
\hline
\end{tabular}

TABLE 3: DISTRIBUTION OF RS360717 GENE POLYMORPHISM IN TWO GROUPS

\begin{tabular}{lcccccc}
\hline Group & $\mathbf{n}$ & \multicolumn{3}{c}{ Genotype } & \multicolumn{2}{c}{ Allele } \\
\hline & & CC & TC & TT & C & T \\
RSA group & 120 & 28 & 55 & 37 & 111 & 129 \\
Control group & 120 & 48 & 50 & 22 & 146 & 94 \\
$\mathrm{t}$ & & & 13.195 & & 16.258 & $<0.001$ \\
$\mathrm{P}$ & & & $<0.001$ & & & \\
\hline
\end{tabular}


TABLE 4: RELATIONSHIP BETWEEN IL-18 GENOTYPES AND HORMONE LEVELS

\begin{tabular}{lcc}
\hline Genotype & $\mathbf{n}$ & $\mathrm{IL}-18(\mathrm{ng} / \mathrm{L})$ \\
\hline rs1946519 & & \\
GG & 18 & $36.17 \pm 8.53$ \\
AG & 58 & $44.21 \pm 10.24$ \\
AA & 44 & $51.09 \pm 11.17$ \\
F, P & & $16.093,<0.001$ \\
rs360717 & & \\
CC & 28 & $37.38 \pm 7.11$ \\
TC & 55 & $43.79 \pm 11.06$ \\
TT & 37 & $50.26 \pm 12.33$ \\
F, P & & $21.276,<0.001$ \\
\hline
\end{tabular}

TABLE 5: LOGISTIC REGRESSION ANALYSIS OF RSA RISK

\begin{tabular}{lcccc}
\hline Genotype & Wald $x 2$ & P & OR & $95 \% \mathrm{Cl}$ \\
\hline rs1946519 & & & & \\
GG & - & - & - & 1.00 \\
AG & 5.117 & 0.016 & 2.468 & $1.154 \sim 3.853$ \\
AA & 6.774 & 0.008 & 2.712 & $1.351 \sim 5.468$ \\
rs360717 & & & & \\
CC & - & - & - & 1.00 \\
TC & 4.852 & 0.029 & 1.973 & $1.017 \sim 2.716$ \\
IT & 4.673 & 0.034 & 1.545 & $0.967 \sim 2.635$ \\
\hline
\end{tabular}

of RSA. IL-18 rs360717 allele can cause His hl61 Arg mutation and antagonize the pro-inflammatory effect of wild-type IL-18 gene ${ }^{[15]}$. The genotypes and distribution of IL-18 (rs1946519) and IL-18 (rs360717) in RSA patients and healthy pregnant women were analyzed. The results showed that the AA genotype and A allele of rs1946519 in RSA group were significantly higher than those in control group $(\mathrm{p}<0.05)$, while the $\mathrm{CC}$ genotype and $C$ allele of rs360717 in RSA group were significantly lower than those in control group $(\mathrm{p}<0.05)$, suggesting that rs1946519 and rs360717 polymorphisms may be associated with RSA. There were significant differences in serum IL-18 levels between the two groups and there were significant differences in serum IL-18 levels between rs1946519 and rs360717 mutants, suggesting that the polymorphism of rs1946519 and rs360717 is associated with RSA susceptibility. It may be that the gene mutation promotes the secretion of IL- 18 by Th18 cells and the balance of Th18/Treg is destroyed, which further affects the balance of serum hormones and induces RSA. Further logistic analysis showed that the relative risk of RSA in rs1946519 AG and AA carriers was 2.012 and 2.545 times of GG allele, respectively and that in rs360717 TC and TT carriers was 1.735 and 1.478 times of $\mathrm{CC}$ allele, respectively. Therefore, we speculate that the $\mathrm{G}$ and $\mathrm{C}$ genotypes of rs1946519 and rs360717 are risk factors for RSA. Previous studies have found that after rs1946519 A allele mutation, peripheral blood monocytes can induce high expression of IL-18 protein, thus increasing the concentration of IL-18 protein in peripheral circulation, breaking the immune balance during pregnancy and causing changes in the internal environment ${ }^{[16]}$. In conclusion, IL-18 rs1946519 polymorphism allele G, rs360717 allele C mutation can affect the serum hormone levels of patients, leading to increased risk of RSA in pregnant women. Therefore, IL-18 gene polymorphism may become one of the important basis for the pathogenesis and treatment of RSA. This study is more to explore the effect of IL-18 gene polymorphism on RSA patients, but did not evaluate the collective immune status. Therefore, it is necessary to study the relationship between IL-18 gene polymorphism and immune related indicators of RSA patients in the next step, in order to further explore the mechanism of IL-18 gene polymorphism and its relationship with RSA patients. Meanwhile, this study focuses on the evaluation of IL18 gene polymorphism in immune related RSA population. The impact of IL-18 gene polymorphism on the susceptibility of RSA patients with other factors (infection, chromosomal abnormalities, male semen abnormalities, etc.) needs to be confirmed by more large-scale studies.

\section{Acknowledgements:}

This work was supported by the Maternal and Child Hospital of Haidian District and Haikou Hospital of the Maternar and Child Health.

\section{Conflicts of interest:}

The authors report no conflicts of interest.

\section{REFERENCES}

1. Işik G, Demirezen Ş, Dönmez HG, Beksaç MS. Bacterial vaginosis in association with spontaneous abortion and recurrent pregnancy losses. J Cytol 2016;33(3):135-40.

2. Wu T, Yin B, Zhu Y, Li G, Ye L, Chen C, et al. Molecular cytogenetic analysis of early spontaneous abortions conceived from varying assisted reproductive technology procedures. Molecular cytogenetics 2016;9(1):1-6.

3. Zhu L, Chen H, Liu M, Yuan Y, Wang Z, Chen Y, et al. Treg/Th17 cell imbalance and IL-6 profile in patients with unexplained recurrent spontaneous abortion. Reprod Sci 2017;24(6):882-90.

4. Ebina Y, Shimada S, Deguchi M, Maesawa Y, Iijima N, Yamada H. Divergence of helper, cytotoxic, and regulatory $\mathrm{T}$ cells in the decidua from miscarriage. Am J Reprod Immunol 2016;76(3):199-204.

5. Moffett A, Chazara O, Colucci F, Johnson MH. Variation of maternal KIR and fetal HLA-C genes in reproductive failure: 
too early for clinical intervention. Reprod Biomed Online 2016;33(6):763-9.

6. Dambaeva SV, Lee DH, Sung N, Chen CY, Bao S, GilmanSachs A, et al. Recurrent pregnancy loss in women with killer cell immunoglobulin-like receptor KIR2DS1 is associated with an increased HLA-C2 allelic frequency. Am J Reprod Immunol 2016;75(2):94-103.

7. Safinia N, Vaikunthanathan T, Fraser H, Thirkell S, Lowe $\mathrm{K}$, Blackmore L, et al. Successful expansion of functional and stable regulatory $\mathrm{T}$ cells for immunotherapy in liver transplantation. Oncotarget 2016;7(7):7563.

8. Winger EE, Reed JL. Low circulating CD4+ CD25+ Foxp3+ $\mathrm{T}$ regulatory cell levels predict miscarriage risk in newly pregnant women with a history of failure. Am J Reprod Immunol 2011;66(4):320-8.

9. Khattri R, Cox T, Yasayko SA, Ramsdell F. An essential role for Scurfin in CD4+CD25+T regulatory cells. Nat Immunol 2003;4(4):337-42.

10. Aluvihare VR, Kallikourdis M, Betz AG. Tolerance, suppression and the fetal allograft. J Mol Med 2005;83(2):8896.

11. Alijotas-Reig J, Melnychuk T, Gris JM. Regulatory T cells, maternal-foetal immune tolerance and recurrent miscarriage: new therapeutic challenging opportunities. Med Clin 2015;144(6):265-8.

12. $\mathrm{Lu} \mathrm{QB}$, Zhu S. Modulation of an aqueous extract of Chinese medicine prescription Anzi Heji on ratio of CD4+CD25+FOXP3+regulatory $\mathrm{T}$ cells in anticardiolipin antibody-positive patients with threatened abortion. Chin J Integr Med 2016:1-6.

13. Ozturk OG, Sahın G, Karacor ED, Kucukgoz U. Evaluation of KIR genes in recurrent miscarriage. J Assist Reprod Genet 2012;29(9):933-8.

14. Ntrivalas EI, Bowser CR, Kwak-Kim J, Beaman KD, GilmanSachs A. Expression of killer immunoglobulin-like receptors on peripheral blood NK cell subsets of women with recurrent spontaneous abortions or implantation failures. Am J Reprod Immunol 2005;53(5):215-21.

15. Yamada H, Shimada S, Kato EH, Morikawa M, Iwabuchi K, Kishi R, et al. Decrease in a specific killer cell immunoglobulinlike receptor on peripheral natural killer cells in women with recurrent spontaneous abortion of unexplained etiology. Am J Reprod Immunol 2004;51(3):241-7.

16. Dakhly DM, Bayoumi YA, Sharkawy M, Allah SH, Hassan MA, Gouda HM, et al. Intralipid supplementation in women with recurrent spontaneous abortion and elevated levels of natural killer cells. Int J Gynaecol Obstet 2016;135(3):324-7.

This is an open access article distributed under the terms of the Creative Commons Attribution-NonCommercial-ShareAlike 3.0 License, which allows others to remix, tweak, and build upon the work non-commercially, as long as the author is credited and the new creations are licensed under the identical terms

This article was originally published in a special issue,
"Evolutionary Strategies in Biomedical Research and
Pharmaceutical Sciences" Indian J Pharm Sci 2021:83(3)
Spl issue;99-103

